\title{
Comparison of carrier parking location in shuttle-based storage and retrieval system to determine optimal retrieval transaction performance
}

\author{
Mohamad Maaroff Bahurdin ${ }^{1 *}$, Hazli Zailani ${ }^{2}$, Jamel Othman $^{1}$ and Tengku Mohd Azahar Tuan Dir ${ }^{1}$ \\ UniKL Robotics and Industrial Automation Center (URIAC) ${ }^{1}$ \\ Industrial Automation Section, Universiti Kuala Lumpur Malaysia France Institute, Bangi, Malaysia ${ }^{2}$
}

Received: 21-October-20121; Revised: 08-April-2021; Accepted: 11-April-2021

(C)2021 Mohamad Maaroff Bahurdin et al. This is an open access article distributed under the Creative Commons Attribution (CC BY) License, which permits unrestricted use, distribution, and reproduction in any medium, provided the original work is properly cited.

\begin{abstract}
Shuttle-based storage and retrieval systems (SBS/RS) are one of the automated warehouse system family that has recently been developed to increase throughput capacity. SBS/RS consists of computer-controlled systems that automatically store and retrieve loads from fixed storage locations with precision, accuracy, and speed. The purpose of this paper is to identify the optimal location for an idle carrier to park, as the common aim of the warehouse manager is to minimize the retrieval transaction time. In this study, two parking locations were designed for the carrier. The first point will be at the pick-up and drop-off station, and the second point will be in the middle of an aisle. Two single tier storage with a carrier model was developed in a simulation environment, each model for each carrier parking parameter. The models run for 24 hours, and then the travel time of retrieval transaction is collected for both models. The transaction time was then analyzed statistically using the T-test Method. It is found that the middle of an aisle dwell point outperformed in terms of minimal travel time compared to dwell on the input/output point.
\end{abstract}

\section{Keywords}

Automated storage, SBS/RS, Dwell location, T-test method.

\section{Introduction}

Shuttle-based storage and retrieval system (SBS/RS) is one of the automated warehouse system family. The system typically consists of static multi-level storage racks, carriers that carry Stock-keeping-units (SKU) in and out of the storage rack. There are two carriers in this system, one called lift, carrying SKU from the point of entry to each tier of storage racks, and secondly, a shuttle carrier installed on each level of the storage rack to carry SKUs into and out of the storage compartment. This system claimed to have an efficient transaction rate as the number of carriers is more compared to the conventional crane-based storage system, just only one carrier for each aisle $[1,2]$.

The typical SBS/RS operation is quite simple. There are two principal transactions, to store the SKU into the storage rack and to retrieve the SKU from the storage rack. SBS/RS delivers the SKU through a carrier running between racking frameworks on a track. Furthermore, the carrier can operate at a level or can move to another rack level.

*Author for correspondence

520
The carrier is powered by the battery and intelligent enough to know when to recharge it $[3,4]$. When an item is required, the carrier will drive to the place of the SKU and pick it up from the rack. When there is no transaction, the carrier park at its designed location or called dwell location [2, 5]. Past research had suggested the dwell location for SBS/RS. The dwell location purposed was at the input/output point [6], at the Point-of-Service-Completion (POSC) [7], and in the middle of the rack. The motive to set a variety of carrier parking location is to have the optimal system throughput performance, that is the rate of transaction per hour [8].

The study in this paper is part of a thorough study for both carriers, the lift and shuttle, dwell points for SBS/ RS systems. Past studies show almost no specific study on this carrier dwell point to study the overall performance of this SBS/RS system. The needs of this study are stated and highlighted by [3]. The objective is to identify the optimal carrier shuttle dwell point that minimizes the response time for the next retrieval transaction. This response time minimization will directly reflect on the overall system throughput performance. 
Thus, for the task, two static dwell location is set, one is at the input/output point and second in the middle of the aisle. We develop two similar simulation models with different dwell locations. The simulation model only consists of single-tier with two racks, a total of 36 storage compartments. One shuttle carrier with one point of input and output. The lift is neglected in this study. The transaction travel time is recorded for 24 hours, and then this travel time was analyzed and compared using statistical T-test method.

\section{Literature review}

Automated warehouse technologies are mostly utilized by distribution companies to cope with high transaction throughput rates and increase customer satisfaction. Advances in automation technology have created a new technology in automated warehousing known as SBS/RS [9, 10]. The conventional Automated storage and retrieval system (AS/RS) used the crane as the machine for storage and retrieval (Storage and retrieval machine, SRM), the SKU from the storage racks. This system is regarded as a Cranebased storage and retrieval system (CBS/RS). A crane is typically placed permanently in an aisle with two storage faces and only one crane to serve the storage and retrieval for that aisle. Thus, this becomes the constraint of the conventional system to achieve higher throughput performance [11].

Numerous studies have been done for this SBS/RS. Most studies focus on system design that contributes to increased output. Various system designs that have been proposed and studied. Each design proposal has been calculated along with the performance of the system. This calculation is done either using mathematical methods or simulations or both.

Reference [12] has done a lot of research on this system. Among his contributions in developing this system are the study of mathematical analysis as well as simulation analysis to model time-paths as well as the study of factors that affect system performance [12-16].

The study concerning the park or dwell location of the carrier in SBS/RS is relatively low compared to the conventional AS/RS. The traditional system received a mass study on the said topic. The basic dwell location used in the CBS/RS is still relevant to be used within this SBS/RS. The existing designated area for SRM dwell is at (1) input point, (2) middle point, (3) input/output point, and (4) last location or known as Point-of-Service-Completion (POSC) [2]. The input point refers to the entrance to the object to be stored in the storage rack. Carriers will always dwell at this location after completing the storage or retrieval instructions. The middle point is the center location of a shelf. The input/output refers to two separate locations, where the shuttle will dwell at either location depends on the last transaction made. If the last transaction was stored, then the shuttle will dwell at the input point and else, the shuttle will dwell at the output point. The last location means the crane will stop and park at the last transaction made.

The performance of SBS/RS calculation is quite complicated as the number of carrier or shuttle is varying. The measure previously made using mathematical analysis, then change to simulate. The simulation tool is regarded as the best method to evaluate the complicated system within the shortest time [17-20].

\section{Methodology}

\subsection{Project flowchart}

This project is focused on the development of the SBS/RS simulation model, which consists of several phases, i.e., study the simulation requirement, simulation model design, simulation development, test, and analyze the simulation result. The flow chart shows the methodology and process flow involved in this research project. As shown in Figure 1, the overall flow process and procedures to authorize and improve the operation of the SBS/RS simulation model through this project research.

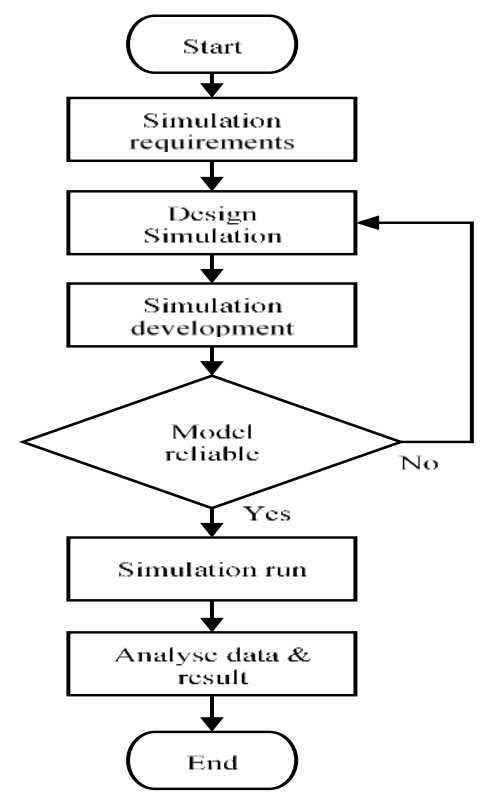

Figure 1 Project flowchart 


\subsection{Summary of simulation parameter}

The data of parameter simulation that was used to develop the SB/RS simulation and the details are shown in Table 1: Specifications of the SBS/RS. This study uses Delmia Quest version 5 software produce by Dassault Systems. The simulation model consists of a single-tier aisle with two rack faces. The total storage compartment is 36 units. There are four main elements in the simulation model. The main components are the storage racks, a carrier, buffers, and parts.

Table 1 Specifications of the SBS/RS

\begin{tabular}{lll}
\hline No & Elements and descriptions & Parameters \\
\hline $\mathbf{1}$ & Racks for storage compartments & Single tier with 2 racks (36 storage compartments) \\
$\mathbf{2}$ & Carrier (Shuttle) & 1 unit \\
& & Design parameter: \\
& & Stopping space: $0.10 \mathrm{~m}$ \\
& & Speed: $21.00 \mathrm{~m} / \mathrm{min}$ \\
& & Loaded speed: $15.00 \mathrm{~m} / \mathrm{min}$ \\
& & Curve speed: $6.00 \mathrm{~m} / \mathrm{min}$ \\
& & Rotation speed: $600 \mathrm{deg} / \mathrm{min}$ \\
& & Acceleration: $360 \mathrm{~m} / \mathrm{min}^{2}$ \\
$\mathbf{3}$ & Buffer & Deceleration: $360 \mathrm{~m} / \mathrm{min}^{2}$ \\
$\mathbf{4}$ & Parts & 2 units $(1$ in-buffer, 1 out-buffer), use the default parameters \\
& & 2 parts \\
\hline
\end{tabular}

\subsection{Run and test the model simulation}

The model simulation run and evaluated after the simulation model SBS/RS has been completed. In this section, several processes and tests carried out to obtain the best results from the simulation. Simulation, modelling was explicitly designed to understand the storage position and load sequence allocation. The model simulation needs to follow the requirement that has been set. If the simulation model is having problems running and testing, the process for developing the model must start again from the first step to identify the problem encountered. For this experiment, both the simulation models run 24 hours. After 24 hours, the data collection was analyzed from both models if there no problem with the simulation during running. The data collection was taken and examined for the first and second model simulation. If there is an error during the simulation model run, the simulation system design was referred to solve the problem described. Based on this part, the data obtained from the simulation model was set as a benchmark depends on the data reliability from the simulation. Run and test the model simulation flowchart shown in Figure 2.

\subsection{Analyze the model performance}

The simulation data from the SBS/RS development was analyzed for the performance of the model throughput and travel time for both simulations. Microsoft Excel is used as a tool to filter all the data from the development of simulations. The data that was filtered is a travel time SBS/RS. Microsoft Excel can present analytics data with a better and easier understanding. So, the data obtained from the simulation that was filtered was analyzed using the statistic method. The statistic value is to define which system is better between two different carriers in the dwell location.

\subsection{Throughput calculation}

The purpose of calculating throughput is to know how many items that can be transferred per hour. This experiment needs to pre-process data to get the amount of throughput per-hour for both simulation models. The throughput calculation steps: (1) Work out the difference (increase) between the two numbers are comparing. (2) Increase $=$ New Number - Original Number. Then, divide the increase by the original number and multiply the answer.

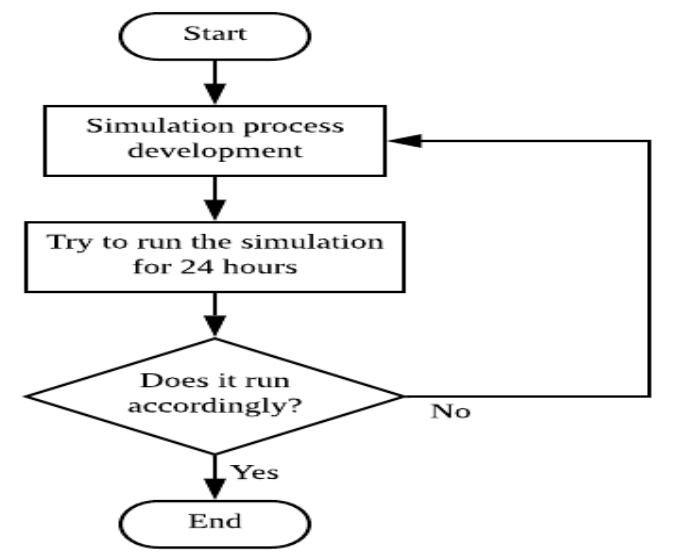

Figure 2 Run and test the model simulation flowchart 


\section{Results}

\subsection{First simulation model layout}

The complete simulation of the first model is shown from the top view in Figure 3. The arrangement made were the part that goes in and out was placed at the beginning of the aisle. Both buffers, in and out buffer set at this input/output point. One carrier in this software, we use an automated guided vehicle (AGV) to act as a carrier. Two storage compartments on each side have a total of 36 storage spaces, 18 on each side. The carrier serves both sides of the storage compartments. This carrier dwell point of this first model is set at the input/output point. Whenever there is no transaction, the carrier will return to that point.

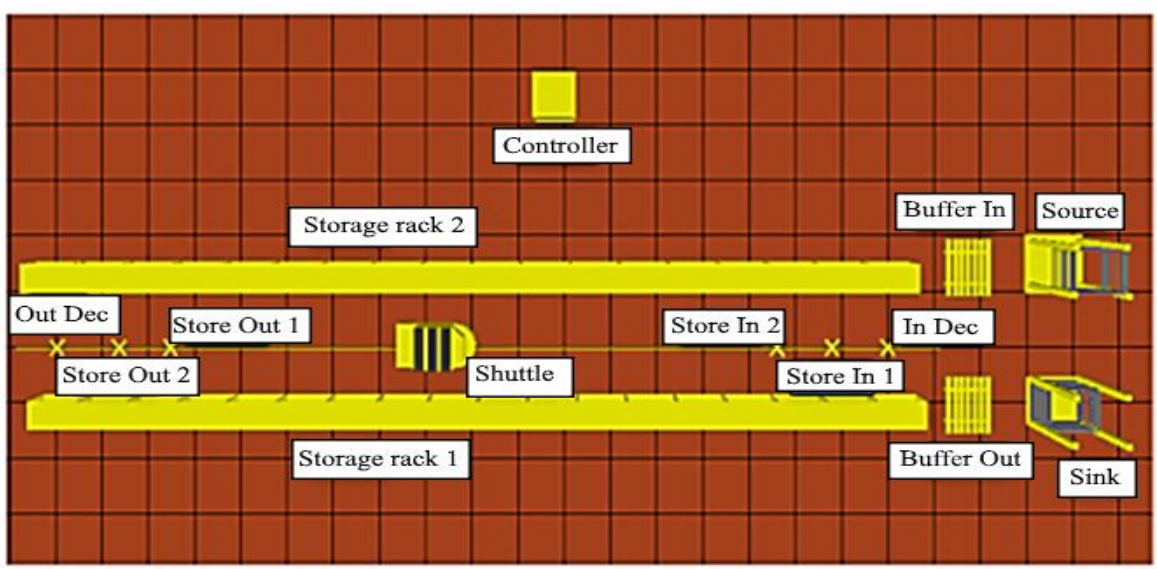

Figure 3 Top view complete simulation model layout

\subsection{Second simulation model layout}

The second model is quite similar to the first model. The difference is that the second model has a new parking decision point, located at the center of the system (aisle) and the setting of an AGV to the park location, as shown in Figure 4.

\subsection{Data analysis}

The raw data from the simulation was filtered and analyzed using Excel. The only data collected is the travel time of the carrier to retrieve the SKU. The time is recorded since it receives the retrieval transaction until the carrier unloads the SKU at the out-buffer. The collection of data that needs to be analyzed is 24 hours.

The simulation data result for Model 1 and Model 2 are recorded in Table 2. The data obtained is used to determine the optimum throughput rate using simulation between the carrier dwell location. The simulation models were running 24 hours to get the complete set of data. Then, the data were analyzed using Excel and MINITAB statistical software.

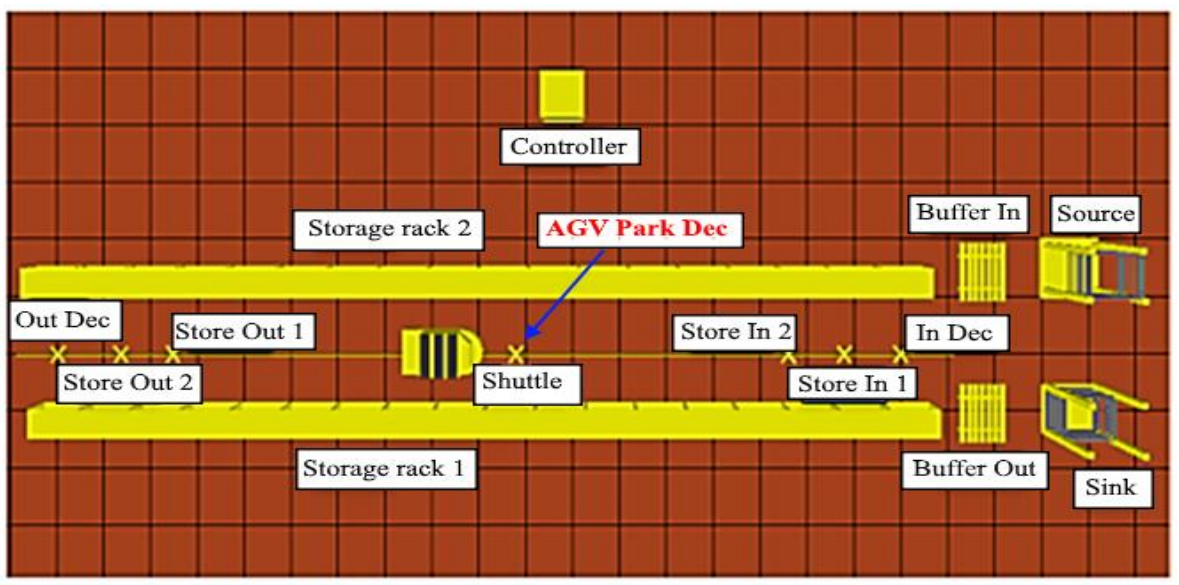

Figure 4 AGV park's decision points 
Mohamad Maaroff Bahurdin et al.

Table 2 The data of Model 1 and Model 2 from the simulation

\begin{tabular}{|c|c|c|c|c|c|}
\hline \multicolumn{3}{|c|}{ Simulation model 1} & \multicolumn{3}{|c|}{ Simulation model 2} \\
\hline Hour & Minutes & Throughput & Hour & Minutes & Throughput \\
\hline 1 & $00: 44$ & 15 & 1 & $00: 39$ & 19 \\
\hline 2 & $00: 39$ & 17 & 2 & $00: 39$ & 21 \\
\hline 3 & $00: 39$ & 20 & 3 & $00: 36$ & 25 \\
\hline 4 & $00: 43$ & 15 & 4 & $00: 41$ & 17 \\
\hline 5 & $00: 38$ & 32 & 5 & $00: 36$ & 26 \\
\hline 6 & $00: 44$ & 20 & 6 & $00: 34$ & 24 \\
\hline 7 & $00: 37$ & 27 & 7 & $00: 36$ & 28 \\
\hline 8 & $00: 38$ & 23 & 8 & $00: 37$ & 27 \\
\hline 9 & $00: 38$ & 22 & 9 & $00: 34$ & 26 \\
\hline 10 & $00: 43$ & 13 & 10 & $00: 40$ & 19 \\
\hline 11 & $00: 35$ & 16 & 11 & $00: 40$ & 18 \\
\hline 12 & $00: 43$ & 13 & 12 & $00: 39$ & 18 \\
\hline 13 & 00:39 & 24 & 13 & $00: 34$ & 23 \\
\hline 14 & $00: 41$ & 25 & 14 & $00: 33$ & 26 \\
\hline 15 & $00: 43$ & 20 & 15 & $00: 33$ & 23 \\
\hline 16 & $00: 37$ & 19 & 16 & $00: 35$ & 25 \\
\hline 17 & $00: 45$ & 19 & 17 & $00: 37$ & 22 \\
\hline 18 & $00: 40$ & 29 & 18 & $00: 32$ & 24 \\
\hline 19 & $00: 40$ & 18 & 19 & $00: 38$ & 16 \\
\hline 20 & $00: 36$ & 26 & 20 & $00: 33$ & 29 \\
\hline 21 & $00: 38$ & 23 & 21 & $00: 36$ & 26 \\
\hline 22 & $00: 39$ & 23 & 22 & $00: 37$ & 25 \\
\hline 23 & $00: 37$ & 28 & 23 & $00: 36$ & 27 \\
\hline 24 & $00: 43$ & 14 & 24 & $00: 39$ & 16 \\
\hline
\end{tabular}

4.4Comparison of the performance between the two models

The hourly throughput comparison chart in Figure 5 shows the line chart of both model simulation results. Generally, it can be observed that the throughput of the Model 2 is higher than the Model 1. The linear trendline chart showing that the throughput of the Model 2 is slightly higher than the Model 1 .

The Paired t-test was conducted to determine and verify the result obtained from the line chart in Figure 5. The test setup is set to determine the mean value of the Model 1 is less than the mean of the Model 2. The result of the test is displayed in Figure 6. The test result shows that the Model 1 mean was less than the Model 2. At this point, based on the data gained from the simulation and the two analysis, it can be said that the Model 2, the midpoint dwell point, has a better performance in terms of system performance. The optimum throughput rate between the two models could be defined based on the data obtained from the simulation. The average throughput for the Model 1 is calculated by summing the total throughput $=504$, then this value is divided by 24 to gain the hourly rate $=21$ pieces/hour. Then the same calculation was made to Model 2, where the total throughput $=550$ and the average was 22.17 pieces/hour. The difference between Model 1 and 2 is about 1.17 hours. The percentage difference is about $5.57 \%$. It can be concluded that from this calculation, the Model 2 throughput rate is higher, about $5.57 \%$. Hence, the Model 2 outperform the result of the Model 1. 


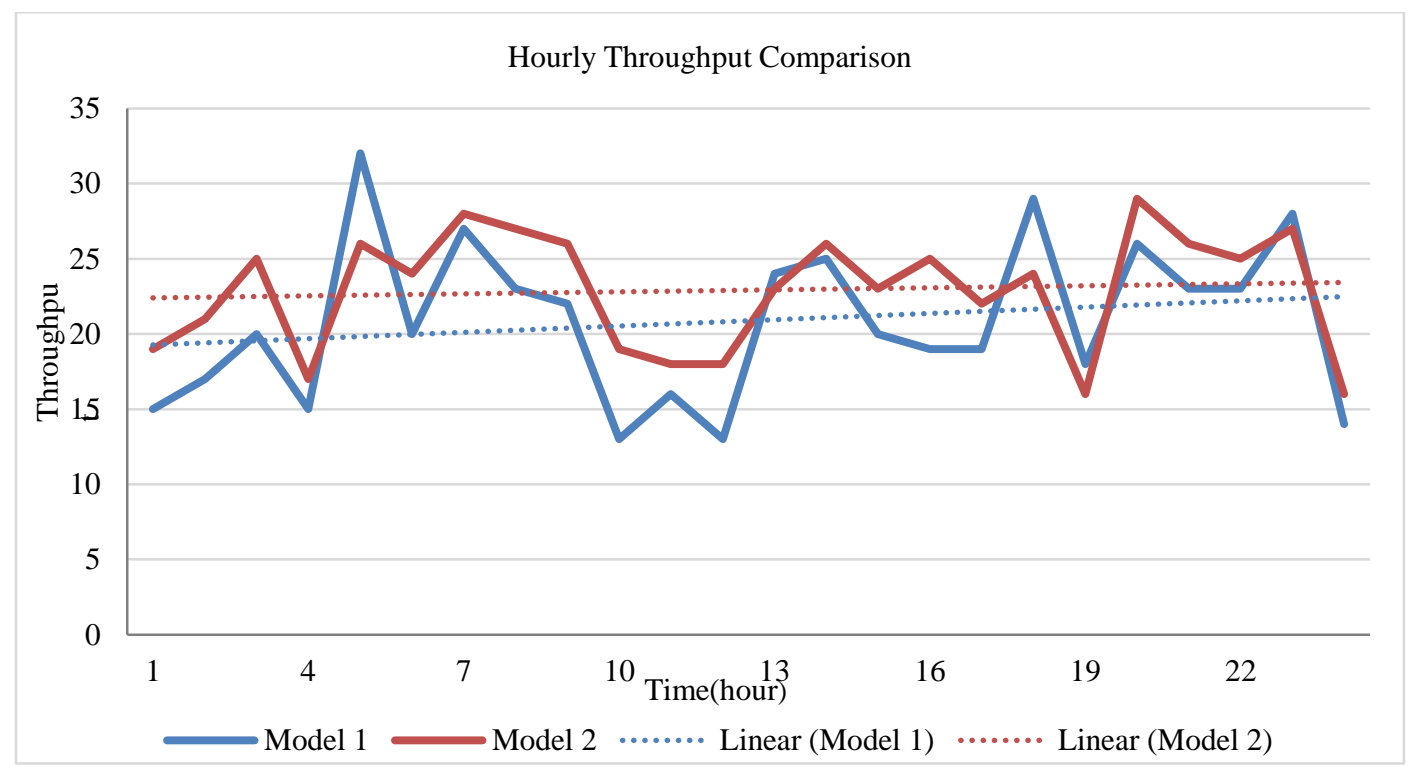

Figure 1 Hourly throughput comparison chart

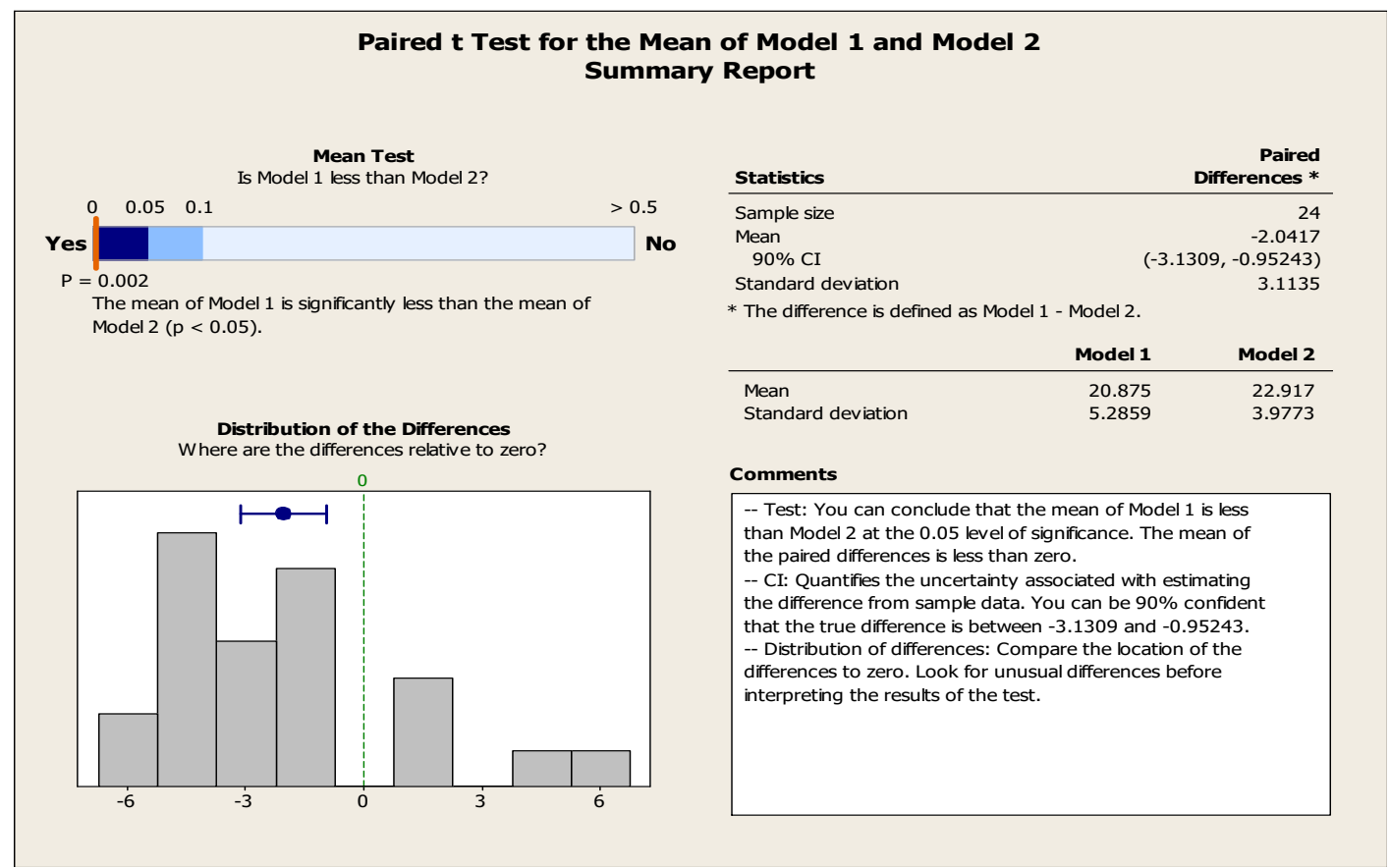

Figure 2 Paired T-Test result

\section{Discussion}

The result from the analysis made earlier shows that Model 2 has a better throughput rate than the Model 1. The model 2 mean value was slightly higher with 22.917 mean value than the Model 1 , just has a mean value of 20.88 . The throughput rate also stated that Model 2 has a higher rate of about $5.57 \%$ than the Model 1. This is the result based on the simulation data gained for 24 hours. The trend line chart in Figure 5 shows that there were enormous differences at the early hour. But, towards to end of the time, the trend line became closer, meaning that the throughput capacity is likely to close to each other.

The trendline prediction was made to analyze the model performance for the next 24 hours. The result of this predict is shown in Figure 7. Based on the chart, it anticipated that the throughput of the Model 1 will 
be higher starting by the hour of 35 . The R 2 value for both trendlines was generated on the chart. The R2 value for Model 1 trendline was 0.0353 (3.53\%), while for Model 2 was $0.0065(0.65 \%)$. Based on these values, the prediction trendlines were too low and considered not good to be a predictive model for the available data. Comparing both percentage $\mathrm{R} 2$ values, it seems that Model 1 is fitted well the trendline compared to the Model 2.
Clearly, this study shows that the Model 2, the dwell at midpoint, outperforms the Model 1, return to input/ output point. This was correct when run for 24 hours. But when predicted based on the 24 hours simulation data, the opposite result obtained. But the prediction result was also weak as indicated by the $\mathrm{R} 2$ value for both models trendline. It can be said that the data is not enough to produce a complete and authoritative study.

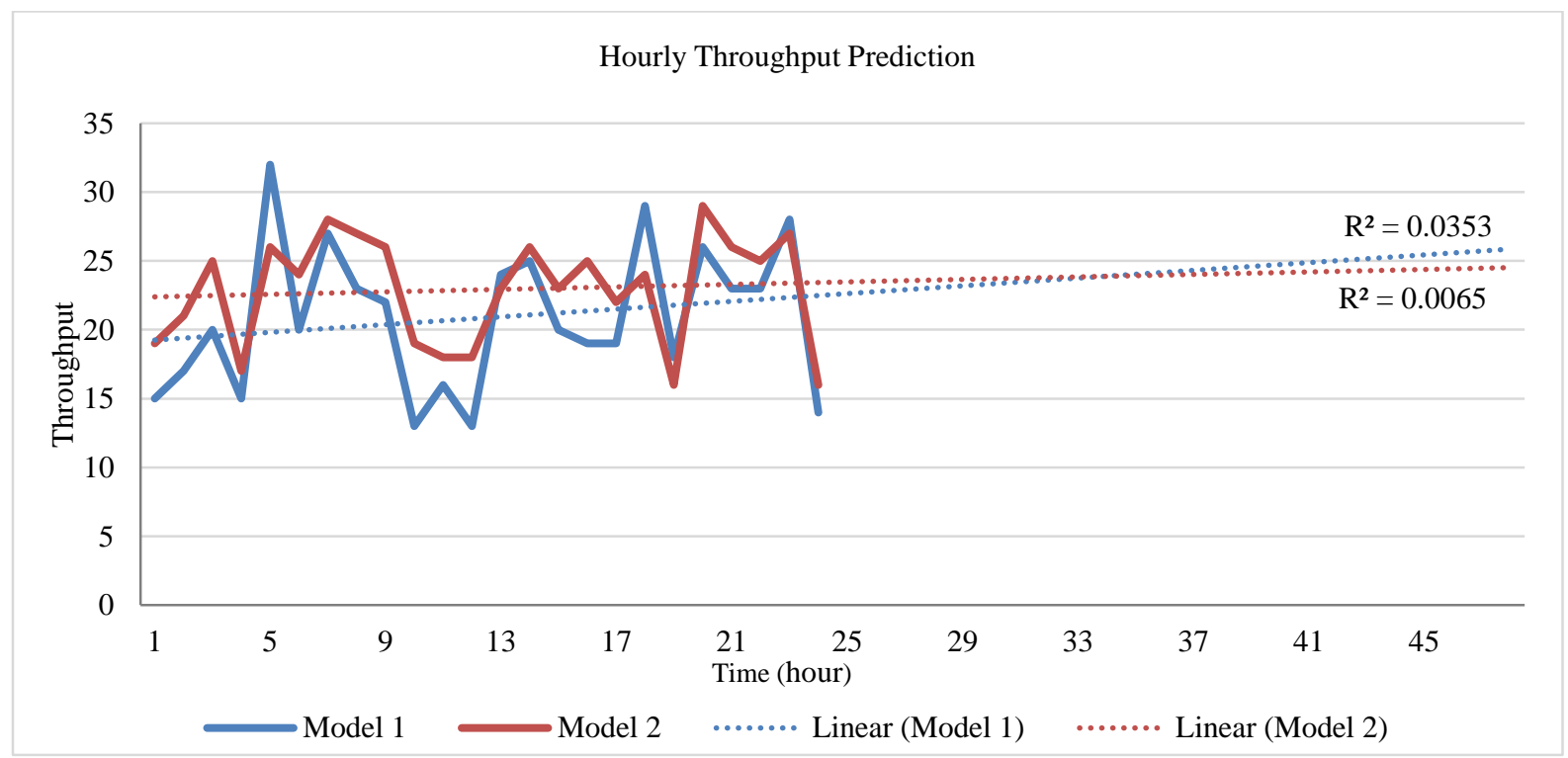

Figure 3 Hourly throughput prediction for the next 24 hours

\section{Conclusion and future work}

The concept of this project is relevant for the comparison of the SBS/RS carrier dwell location to determine the optimum throughput rate using simulation. This research project and data analysis can be used as a reference for others, precisely the company that wants to run the storage system before implementing the real system because the construction of the real system is costly. It shows that many people in the industry, in general, can benefit from this research project. The storage system plays an important role where the efficiency of the storage system will have a significant impact on the performance of the throughput of the company.

This study shows that the SBS/RS retrieval transaction rate is much better if the carrier dwell location is set in the middle of the aisle point. Compared to the carrier dwelling at the input / output point, the middle point gained more than $5.57 \%$ throughput. Both models have the same modelling parameters, except the location of carrier dwell is different.
This research project has plenty of room to improve in the future. For future research, new software suggested that has the same functionality but more user-friendly. The simulation can be developed as a further reference, especially in the industry when it wants to implement the SBS/RS system. The potential of the simulation which is it possible to model and analyze the operation of a real plan. Other than that, the filtering data can be use python library called a pandas data frame. By using this library, we can filter the raw data a lot faster. Other than, for the future experiment is to add another tier to investigate between the performance first experiment has any different from the second experiment.

\section{Acknowledgment}

None.

\section{Conflicts of interest}

The authors have no conflicts of interest to declare. 


\section{References}

[1] Lerher T, Borovinsek M, Ficko M, Palcic I. Parametric study of throughput performance in SBS/RS based on simulation. International Journal of Simulation Modelling. 2017; 16(1):96-107.

[2] Regattieri A, Santarelli G, Manzini R, Pareschi A. The impact of dwell point policy in an automated storage/retrieval system. International Journal of Production Research. 2013; 51(14):4336-48.

[3] Azadeh K, De Koster R, Roy D. Robotized and automated warehouse systems: review and recent developments. Transportation Science. 2019; 53(4):917-45.

[4] Zou B, Xu X, De Koster R. Evaluating battery charging and swapping strategies in a robotic mobile fulfillment system. European Journal of Operational Research. 2018; 267(2):733-53.

[5] Ventura JA, Pazhani S, Mendoza A. Finding optimal dwell points for automated guided vehicles in general guide-path layouts. International Journal of Production Economics. 2015; 170:850-61.

[6] Roy D, Krishnamurthy A, Heragu S, Malmborg C. Queuing models to analyze dwell-point and cross-aisle location in autonomous vehicle-based warehouse systems. European Journal of Operational Research. 2015; 242(1):72-87.

[7] Epp M, Wiedemann S, Furmans K. A discrete-time queueing network approach to performance evaluation of autonomous vehicle storage and retrieval systems. International Journal of Production Research. 2017; 55(4):960-78.

[8] Groover MP. Automation, production systems, and computer-integrated manufacturing. Pearson Education India; 2016.

[9] Yetkin Ekren B. Graph-based solution for performance evaluation of shuttle-based storage and retrieval system. International Journal of Production Research. 2017; 55(21):6516-26.

[10] Bahurdin MM, Othman J, and Dir TMAT. Developments shuttle based storage and retrieval system current and future. International Journal of Advanced Science and Technology.2020; 29(8S): 4430-7.

[11] Ekren BY, Heragu SS. Performance comparison of two material handling systems: AVS/RS and CBAS/RS. International Journal of Production Research. 2012; 50(15):4061-74.

[12] Lerher T, Ekren BY, Dukic G, Rosi B. Travel time model for shuttle-based storage and retrieval systems. The International Journal of Advanced Manufacturing Technology. 2015; 78(9-12):1705-25.

[13] Lerher T, Šraml M, Potrč I. Simulation analysis of mini-load multi-shuttle automated storage and retrieval systems. The International Journal of Advanced Manufacturing Technology. 2011; 54(1-4):337-48.

[14] Lerher T. Aisle changing shuttle carriers in autonomous vehicle storage and retrieval systems. International Journal of Production Research. 2018; 56(11):3859-79.
[15] Alam Z, Khursheed A, Chaudhary RK. Modeling simulation and performance evaluation of low voltage power line communication channel. International Journal of Advanced Technology and Engineering Exploration. 2018; 5(46):308-17.

[16] Pundir AS, Singh K, Dohare RK. Simulation of fixed bed catalytic reactor through adomian decomposition method and reduced differential transform method. International Journal of Advanced Technology and Engineering Exploration. 2016; 3(22): 131-6.

[17] Daaif J, Zerraf S, Tridane M, Chbihi M. Computer simulations as a complementary educational tool in practical work: application of monte-carlo simulation to estimate the kinetic parameters for chemical reactions. International Journal of Advanced Trends in Computer Science and Engineering. 2019; 8(1.4): 249-54.

[18] Sakri FM, Azizan MA, Haniff MF, and Syafiq Sama M U. A simulation study on reverse jet during air-core vortex formation. International Journal of Advanced Trends in Computer Science and Engineering. 2019; 8(4): 1777-82.

[19] Kashyap V, Kapoor D. An efficient framework for the automatic and dynamic load distribution in IOT. International Journal of Advanced Technology and Engineering Exploration. 2019; 6(61):267-73.

[20] Pateliya M, Ohri J. Position control of robot manipulator by torque equillibrium method. International Journal of Advanced Technology and Engineering Exploration. 2016; 3(25):211-6.

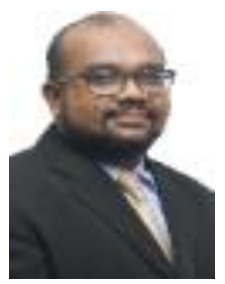

Mohamad Maaroff Bahurdin is a $\mathrm{PhD}$ candidate in Industrial Automation Section, Malaysia France Institute, Universiti Kuala Lumpur, Bangi, Selangor, Malaysia. He was awarded Master of Science in Manufacturing System Engineering from Universiti Putra Malaysia. His research work during his master study was finding the optimal machining parameter for cast iron machining. He gained his bachelor's degree from France in 2005 in Industrial Engineering domain.

Email: maaroff@unikl.edu.my

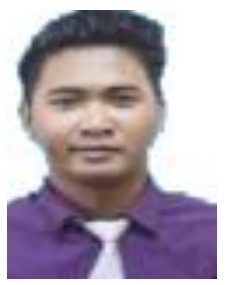

Hazli Zailani born on 23rd February 1995 in Muar, Johor, Malaysia. He is currently in his last fourth-year study in Bachelor of Engineering Technology in Mechatronic at Universiti Kuala Lumpur., Bangi. He is a diploma holder in Industrial Electronic (Mechatronic) gained from British Malaysia Institute, Bangi and a certificate of Oil \& Gas Electro-Mechanical and Instrumentation Technology that he gained from Johor Skill Development Center (PUSPATRI).

Email: hazlizailani@gmail.com 
MM Bahurdin et al.

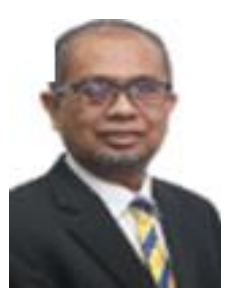

Jamel Othman gained his $\mathrm{PhD}$ in Manufacturing. Engineering from an Ireland university. He did his Master of Science in Industrial Technology at National University of Malaysia (UKM). He obtained his Bachelor of Science in Electrical from France University. He is now Head of Campus Malaysia France Institute, Universiti Kuala Lumpur, Bangi, Selangor, Malaysia.

Email: jamel@unikl.edu.my

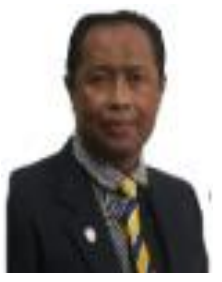

Tengku Mohd Azahar Tuan Dir is now working as Deputy Dean Academic \& Technology, Malaysia France Institute, Universiti Kuala Lumpur, Bangi, Selangor, Malaysia. He obtained his $\mathrm{PhD}$ from France university. 